\title{
DESIGN CHALLENGES ENCOUNTERED IN A PROPULSION-CONTROLLED AIRCRAFT FLIGHT TEST PROGRAM
}

\author{
Trindel Maine, John Burken,"* Frank Burcham ${ }^{\dagger}$ \\ NASA Dryden Flight Research Center \\ P.O. Box 273 \\ Edwards, California 93523-0273 \\ Peter Schaefer ${ }^{\dagger \dagger}$ \\ University of Southern California \\ University Park, EEB 306 \\ Los Angeles, CA 90089-2563
}

\begin{abstract}
The NASA Dryden Flight Research Center conducted flight tests of a propulsion-controlled aircraft system on an F-15 airplane. This system was designed to explore the feasibility of providing safe emergency landing capability using only the engines to provide flight control in the event of a catastrophic loss of conventional flight controls. Control laws were designed to control the flightpath and bank angle using only commands to the throttles. Although the program was highly successful, this paper highlights some of the challenges associated with using engine thrust as a control effector. These challenges include slow engine response time, poorly modeled nonlinear engine dynamics, unmodeled inlet-airframe interactions, and difficulties with ground effect and gust rejection. Flight and simulation data illustrate these difficulties.
\end{abstract}

\section{Nomenclature}

EMD engine model-derivative

HIDEC highly integrated digital engine control

$K_{\mathrm{n}} \quad$ propulsion-controlled aircraft control system gain

MDA McDonnell Douglas Aerospace, St. Louis, Missouri

NASA National Aeronautics and Space Administration

PCA propulsion-controlled aircraft

$\alpha \quad$ angle of attack, deg

\footnotetext{
"Aerospace Engineer. Member AIAA.

**Aerospace Engineer.

${ }^{\dagger}$ Chief, Propulsion Branch. Associate Fellow AIAA.

${ }^{\dagger+}$ Graduate Student.

Copyright $\odot 1994$ by the American Institute of Aeronautics and Astronautics, Inc. No copyright is asserted in the United States under Title 1, U.S. Code. The U.S. Govemment has a royalty-free license to exercise all rights under the copyright claimed herein for Govemmental purposes. All other rights are reserved by the copyright owner.
}

\section{Introduction}

Current aircraft flight control systems employ extensive redundancy to ensure reliable performance. Although rare, major failures of the flight control system almost always result in the loss of the aircraft. Several loss-of-flight-control failures have occurred in multiengine aircraft in which a functioning propulsion system was used to regain limited control of the aircraft. ${ }^{1}$

These failures led to an investigation at the NASA Dryden Flight Research Center (NASA Dryden) to determine the feasibility of using the normal propulsion system to provide flight control capability in several multiengine aircraft. Early investigations, based on both flight and simulation, showed that the engines were capable of providing substantial control capability for most multiengine airplanes. Differential thrust induces yaw that, through the normal dihedral effect, results in roll. For stable airplanes with a fixed surface position, symmetric thrust changes cause an initial change in speed that is converted to pitch change and results in the airplane returning to the trim speed. Results of these studies and recommended procedures for manual throttles-only control have previously been presented. ${ }^{2}$

The basic result for most of the multiengine airplanes studied in these early investigations was that although the throttles provided the gross control authority needed to fly the airplane to a reasonable landing area, the fine control needed to safely and repeatedly land the airplane on a runway was lacking. Because the gross control capability appeared to exist, the next step was to investigate whether a closed-loop flight control system could sufficiently simplify the task of controlling the airplane with the throttles to repeatedly make safe landings. Such a system would be a reasonable candidate for an alternative backup control system. Augmented control systems were first investigated in simulations of a B-720 transport $^{3}$ and an F-15 airplane. ${ }^{4}$ 
Based on highly encouraging simulation results and the availability of the NASA F-15 airplane with the necessary digital control systems, a limited program was started in 1991 to take the propulsion-controlled aircraft (PCA) concept to flight test. The objectives were to investigate the PCA system over a small flight envelope of 150 to 190 knots at altitudes of up to $10,000 \mathrm{ft}$ and attempt landings if the performance was adequate.

The system clearly demonstrated the ability to easily fly the airplane over extended periods in low-speed cruise, provide safe landing capability with a manageable workload in light turbulence, and successfully regain level flight when engaged from a few unusual attitudes. ${ }^{5}$ Near the end of the program, six guest pilots were asked to fly and evaluate the system as a backup flight control. Their reactions were generally favorable and have previously been reported. ${ }^{6}$

Compared to conventional flight control surfaces, the engines are slow and have limited control effectiveness. These engine characteristics increase the vulnerability of the system to outside disturbances. Similarly, the ability of the system to promptly respond to aerodynamic changes is limited. Normally negligible effects such as inlet-airframe interactions become significant when the engine becomes the control effector. This paper discusses the challenges encountered during the flight test program that were related to relying on the engines as the sole flight control effector. Difficulties with modeling the engines, inlet-airframe interactions, ground effect, and gust rejection are discussed.

\section{Airplane Description}

The F-15 aircraft is a high-performance fighter aircraft manufactured by McDonnell Douglas Aerospace (MDA), St. Louis, Missouri (fig. I). The aircraft has a high wing with $45^{\circ}$ of leading-edge sweep and has twin vertical tails. The F-15 aircraft is powered by two Pratt \& Whitney (West Palm Beach, Florida) FI00 afterburning turbofan engines symmetrically mounted, $4.25 \mathrm{ft}$ center to center, in the aft fuselage. As is typical of fighter aircraft, the propulsion system is highly integrated into the fuselage. The NASA F-15 airplane was used as the testbed aircraft for the highly integrated digital engine control (HIDEC) program for several years, and thus was well instrumented and had research computer capability.

The engines installed in the NASA F-15 airplane are developmental F100 engine model-derivative (EMD) engines designated PW 128 (Pratt \& Whitney, West Palm Beach, Florida). These engines include a redesigned fan (later incorporated into the Pratt \& Whitney F100-PW-229 engine), higher turbine temperature capability, and a 15-segment augmentor. Prototype engine control system software incorporated in these EMD engines produces slower engine response characteristics at low power settings than those of the production engines. For the PCA tests, afterburning was not used, and throttle settings were limited to intermediate and below. Below intermediate power, the engine is controlled to the fan speed scheduled as a function of throttle angle and flight condition. At low power settings with the gear extended, the nozzle opens

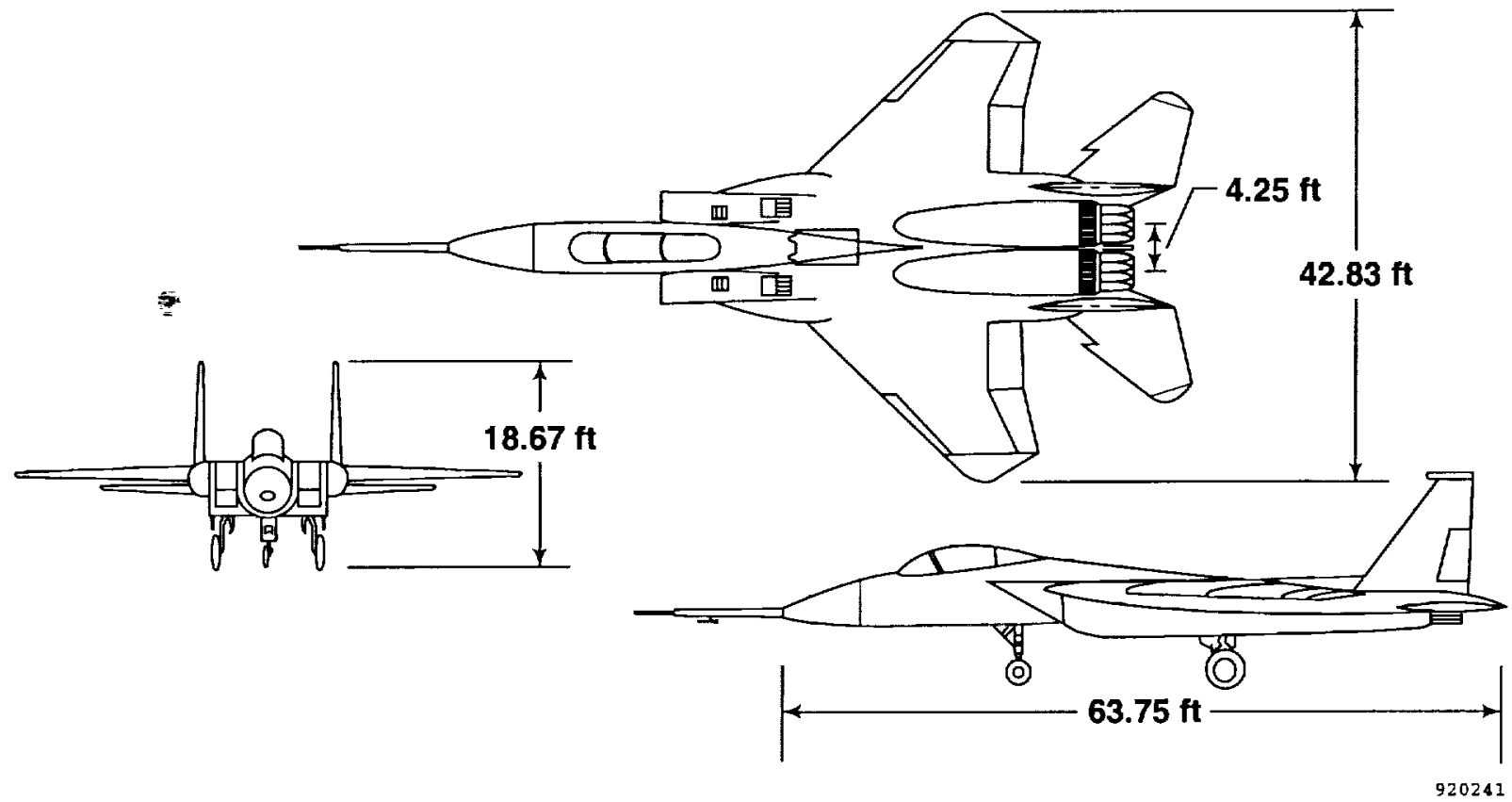

Figure 1. The NASA F-15 highly integrated digital engine control (HIDEC) flight research aircraft. 
with decreasing power lever angles to further reduce thrust in preparation for landing.

The inlets are external compression, horizontal ramp inlets with variable geometry and are mounted on the sides of the forward fuselage. A variable capture area is attained by rotating the inlet cowl about a point near the lower cowl lip. At subsonic speeds, the cowl angle is normally positioned by the inlet control system as a function of angle of attack. When a loss of hydraulic power occurs, the inlets rotate to the full-up position. The full-up position is also selectable by the pilot, and all PCA flights were flown with the inlet in this position.

The NASA F-15 airplane has the standard mechanical flight control system with hydraulic actuators, but the control augmentation system is digital instead of the standard analog. This control augmentation system was turned off. Additionally, the mechanical pitch and roll ratio changer system was set to the emergency mode so that the flight control surfaces only responded to direct pilot inputs. Using this configuration, a loss of hydraulic power could be simulated simply by instructing the pilot not to move the stick or rudder pedals. The ability to instantly regain conventional unaugmented flight control if the pilot felt uncomfortable with the PCA system was preserved. The only hardware modification made to the airplane was the addition of a two-thumbwheel control panel used to input pilot commands to the PCA control system.

\section{Simulation}

Real-time simulations of the F-15 airplane are available at NASA Dryden and at MDA. These simulations predate the PCA project and have been used to support a wide variety of flight research and test programs. Both simulations required significant modifications beyond just adding the PCA control logic to support the PCA program. The changes made to the MDA simulation have previously been discussed. ${ }^{7}$ The high-authority control augmentation system of the F-15 aircraft effectively masks many modeling errors that become significant when trying to use much lower bandwidth control effectors. Major efforts went into getting an accurate model of ground effect on this airplane and into modeling an unanticipated interaction between the airframe and the inlet. These two topics are discussed in separate sections.

Initially, the engine models in both simulations were inadequate for PCA work. Engine dynamics were poorly modeled by the preexisting engine model. Additionally, for the NASA F-15 engines at low power settings with the gear extended, the nozzles open with decreasing throttle to further reduce thrust in preparation for landing. This effect was not modeled, and virtually all PCA flight test was done with the gear down. Note that most flight research is not particularly sensitive to engine dynamics. Generally, the engine is in steady state before starting an experimen- tal maneuver. Because good dynamic engine simulations tend to be large, complex programs that are difficult to run in real time, accurate engine dynamics are frequently neglected in flight simulations.

A real-time engine model was developed from a Pratt \& Whitney component-based dynamic simulation. ${ }^{7}$ This model used a first-order lag and variable time constant and then applied engine rate limits to provide reasonably accurate gross thrust and ram drag throughout the PCA flight envelope. Gyroscopic effects of the engine spooling were also added to the model because they introduce a small asymmetry to thrust commands. Separately modeling the effects of gross thrust and ram drag also improved the simulation and flight data match. ${ }^{4}$

Flight tests of the PCA system were generally performed with the gear and flaps down at speeds close to the minimum in the aerodynamic database. Unlike the database for most of the F-15 flight envelope, the low-speed aerodynamic database did not match flight data well, particularly in the longitudinal axis. The flap model was believed to be degrading the match quality, so rough corrections were made to the flap lift, drag, and pitching moment increments. The corrections were made primarily by trying to match the trim speed and angle of attack of the simulation to the trim speed and angle of attack seen in flight. A parameter estimation study to better define the low-speed aerodynamics would have been desirable but was beyond the scope of this PCA demonstration. The relatively high level of modeling uncertainty limited confidence in aggressive control law design techniques.

\section{Propulsion-Controlled Aircraft Control}

Lateral-directional PCA control is obtained by differential thrust inducing yaw that, through the normal dihedral effect, results in roll. Pitch control using only the throttles is more complex. For stable airplanes with a fixed surface position, symmetric thrust changes cause an initial change in speed that is converted to pitch change and results in the airplane returning to the trim speed. This trade between speed and pitch results from the phugoid oscillation. For aircraft that have their engines located on the vertical center of gravity, damping the phugoid is the primary mechanism for obtaining pitch control. Additionally, if the thrust line is inclined to the flightpath, the vertical component of thrust directly increases the vertical velocity. This effect increases with angle of attack. The principles of throttles-only control have previously been detailed. ${ }^{2.4}$

With the surfaces locked in a fixed position, the trim airspeed of a stable airplane is only slightly affected by changes in engine thrust. Control system failures that occur at faster than safe landing speeds pose potential problems for a PCA control system; however, other means of slowing the airplane often exist. For the NASA F-15 airplane, adequate deceleration was demonstrated from 
subsonic cruise conditions by lowering the gear, moving the inlets to the emergency position, and lowering the electrically driven flaps. ${ }^{6}$ Additionally, for the NASA F- 15 airplane, fuel burn shifts the center of gravity aft and thus reduces the trim airspeed by nearly $1 \mathrm{knot} / \mathrm{min}$ in level flight.

The baseline PCA control laws are composed of two tracking loops that were primarily developed by $\mathrm{MDA}^{7}$ The longitudinal control law tracks commanded flightpath angle (fig. 2(a)), and the lateral-directional axis tracks commanded bank angle (fig. 2(b)). No mechanism exists for directly controlling the aircraft speed.

The longitudinal control law (fig. 2(a)) tracks flightpath angle and provides phugoid damping using feedbacks for flightpath angle and flightpath angle rate. An optional velocity feedback path is used to respond to transient adverse pitching motion caused by inlet airflow and airframe interactions at higher speeds. This interaction is discussed in more detail later. A proportional-plus integral path is included to trim the aircraft to a steady-state operating condition upon control law start-up or as a pilot option. This trim loop is turned off after a steady-state condition has been reached, and the bias generated by the trim loop is thereafter included as a constant in the computation of the forward path.

The lateral-directional control law (fig. 2(b)) tracks bank angle and provides dutch roll damping using stability axis yaw rate and bank-angle feedbacks. An integral path is included to trim bank angle to steady state upon control law start-up or as a pilot option. When the integral path is turned off, the final bias is included as a constant bias in the forward path.

\section{Inlet-Airframe Interactions}

One unanticipated problem had a major impact on the F-15 PCA flight test program. During the control law design process, a limited number of flights were flown at the intended landing speed of 170 knots, and the pilot attempted to fly the airplane manually using the throttles. The initial report was that this task was significantly more difficult than simulation studies had shown, jeopardizing the potential success of the project. A close examination of the flight and simulation data showed that there was a transient pitch-up response to pulling the throttles back. The findings of this study were that a decrease in the inlet velocity and a corresponding increase in the pressure on the overhanging inlet ramps were causing a small, upward-pitching moment. ${ }^{4}$

A piecewise linear increment to the pitching moment as a function of inlet airflow was developed from flight data and added to the simulations. This addition substantially improved the ability of the simulation to match the flight data. Based on this new simulation model, a velocity feedback was added as an option to the longitudinal control law design to ameliorate the adverse pitch response. ${ }^{7}$ The velocity feedback definitely helped but provided a less than satisfactory pitch response, especially for the precise control needed for final approach and landing.

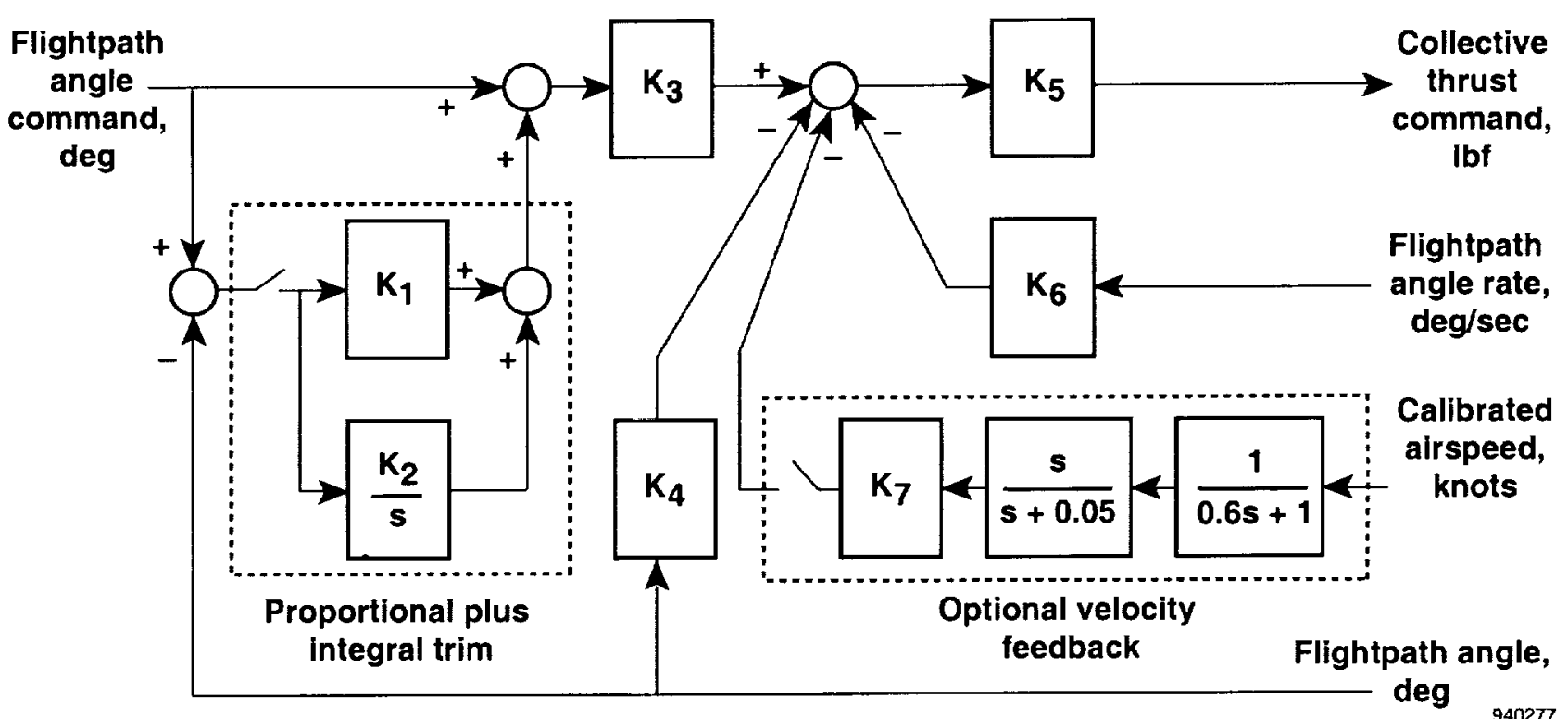

(a) Longitudinal control law.

Figure 2. Propulsion-controlled aircraft control laws. 


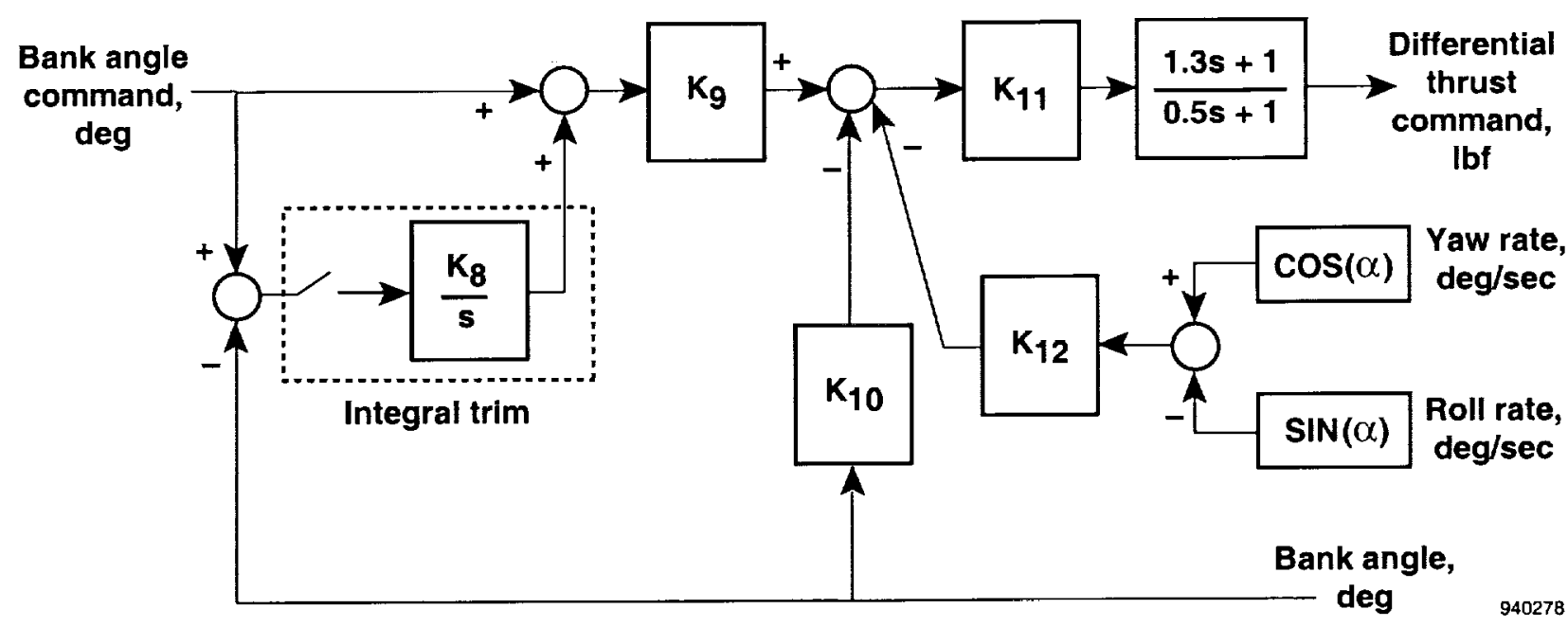

(b) Lateral-directional control law.

Figure 2. Concluded.

To better understand this inlet airflow problem, additional flights were made to evaluate the ability to fly the airplane using manual throttles throughout the range of acceptable landing speeds, 150 to 190 knots. At the lower trim speeds, the resulting trim angle of attack was above $9^{\circ}$, and the inlet mass flow ratios were $>1$. At these conditions, the adverse pitching effect was not present. The decision was made to minimize the inlet airflow effects by changing the intended PCA landing speed to 150 knots. Flying at this speed required lowering the flaps, which are electrically driven on the NASA F-15 airplane.

The inlet airflow effect is easily accommodated by the normal flight controls and would often be overlooked in an airplane simulation. Because of the limited control power available when using the engines as the sole control effectors, however, normally neglected effects are likely to be significant. Moreover, the direct coupling of inlet airflow changes to control system commands makes the airflow effect a significant problem for a propulsion-only control design. Problems of this nature are most likely to occur on aircraft with highly integrated propulsion systems, as is common in fighter aircraft, where inlet-airframe interactions are strong. The podded engines with simple inlets found on most subsonic aircraft should have minimal problems with inlet-airframe interactions.

\section{Ground Effect}

The F-15 aircraft is known to pitch down when in ground effect. Although this downward pitch is easily accommodated by the normal control system, there was concern that an uncommanded pitch down just before touchdown was a potential problem because of the slow response of the PCA system. Longitudinal control power from the engines is highly limited on the F-15 airplane. A $2^{\circ}$ change in flightpath angle takes 10 to $15 \mathrm{sec}$. After the pilot enters ground effect, there is little time left for the PCA system to apply an adequate correction before landing.

Based on this concern, an in-flight investigation of dynamic ground effect was conducted for the F- 15 aircraft prior to the PCA flight program. Data were collected for 24 landings on 7 flights. The flight test technique for the landings investigating ground effect consisted of flying stabilized, constant glide slope approaches into ground effect. Once in ground effect, the pilot attempted to maintain a constant pitch attitude and minimize longitudinal stick and throttle inputs. This study has been documented in detail. ${ }^{8}$ Using this study, ground effect-induced changes in lift, pitching moment, and drag were determined as a function of height above ground, sink rate and velocity. These changes were incorporated in the simulator and significantly improved the ability of the simulation to match the flight data when within $20 \mathrm{ft}$ of the ground.

Simulator studies based on this revised simulation were then used to predict the expected sink rate at touchdown based on the sink rate upon entering ground effect. As figure 3 shows, this revised ground-effect model substantially changed the predicted sink rate at touchdown for shallow glide slopes. The revised simulation showed that for shallow glide slopes, the expected sink rates at touchdown were safely below the $10 \mathrm{ft} / \mathrm{sec}$ gear limit for a fully loaded F-15 airplane.

Based on these studies and a growing confidence in the PCA system from numerous low approaches, two touchand-go landings were performed using the PCA controls. 


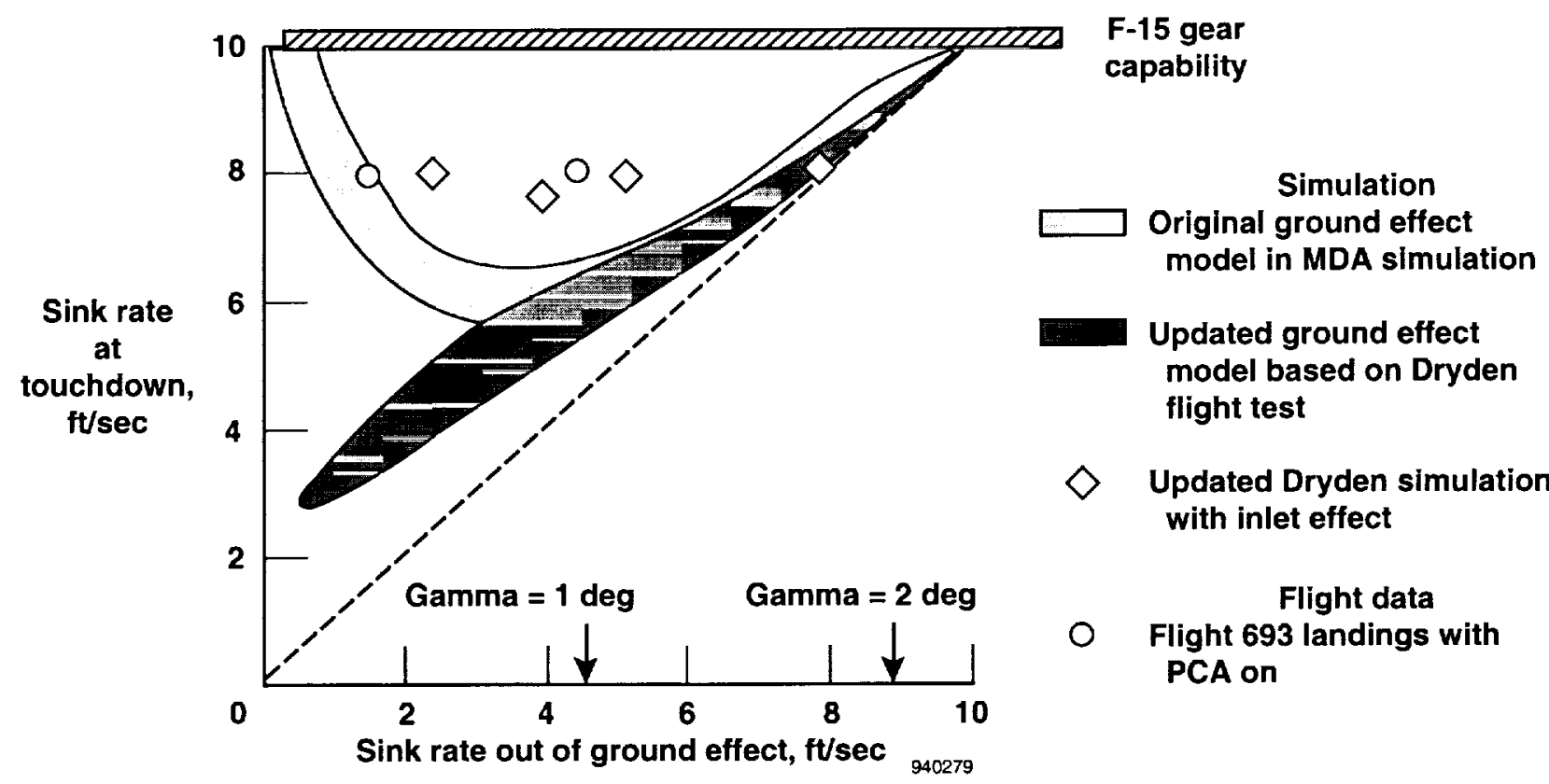

Figure 3. Comparison of predicted and measured ground effects for F-15 propulsion-controlled aircraft landings at a speed of 150 knots.

The circles in figure 3 show both landings resulted in sinkrates significantly higher than predicted and uncomfortably close to the gear limit. In both landings, the pilot decoupled the system during the last half second before touchdown while pulling back the stick to reduce the sink rate. These landings undoubtedly would have been safe PCA landings without the stick input; however, in a test program, repeatedly straining the landing gear is not desirable. Therefore, no further landings were attempted.

The question remained as to why the sink rates observed in these two landings were so much higher than the predictions. After the flight program was completed, continued analysis of flight data was combined with an extrapolation of the available wind tunnel data. This combination led to revising the model of the aerodynamic characteristics of the inlet when locked in the full-up emergency position and extending the model of the inlet airflow effect to a larger angle-of-attack range. Using this improved model, the simulation did an excellent job of predicting the sink rate observed during the two touchand-go landings, as shown by the diamonds in figure 3 . The primary difference between the earlier ground effect investigation flights and these PCA landings was that the PCA system was increasing thrust in an attempt to counter the pitch down (fig. 4). The ground effect-induced pitch down reduced the angle of attack into the range where the adverse inlet airflow interactions occurred, resulting in an increased pitch down rather than the intended pitch up. As figure 4 shows, the simulation now does an excellent job of modeling the approach.

\section{Lateral Gust Sensitivity}

Like all modern fighter aircraft, the F-15 aircraft was designed to have very fast lateral dynamics. The fast lateral dynamics are achieved in part by having an aircraft design where roll rate is sensitive to small deflections of control surfaces. This design allows the F-15 aircraft to achieve roll rates as high as $200 \mathrm{deg} / \mathrm{sec}$ using the stabilators as the primary control effectors. The disadvantage of high roll rate sensitivity is that the unaugmented F-15 aircraft is very sensitive in the roll axis to atmospheric disturbances such as turbulence and gusting. With a fully functional F-15 aircraft, atmospheric disturbances are not a problem because the stabilators have a relatively high control bandwidth. Sufficient control effectiveness exists to respond quickly to pilot commands and counter typical atmospheric disturbances. 

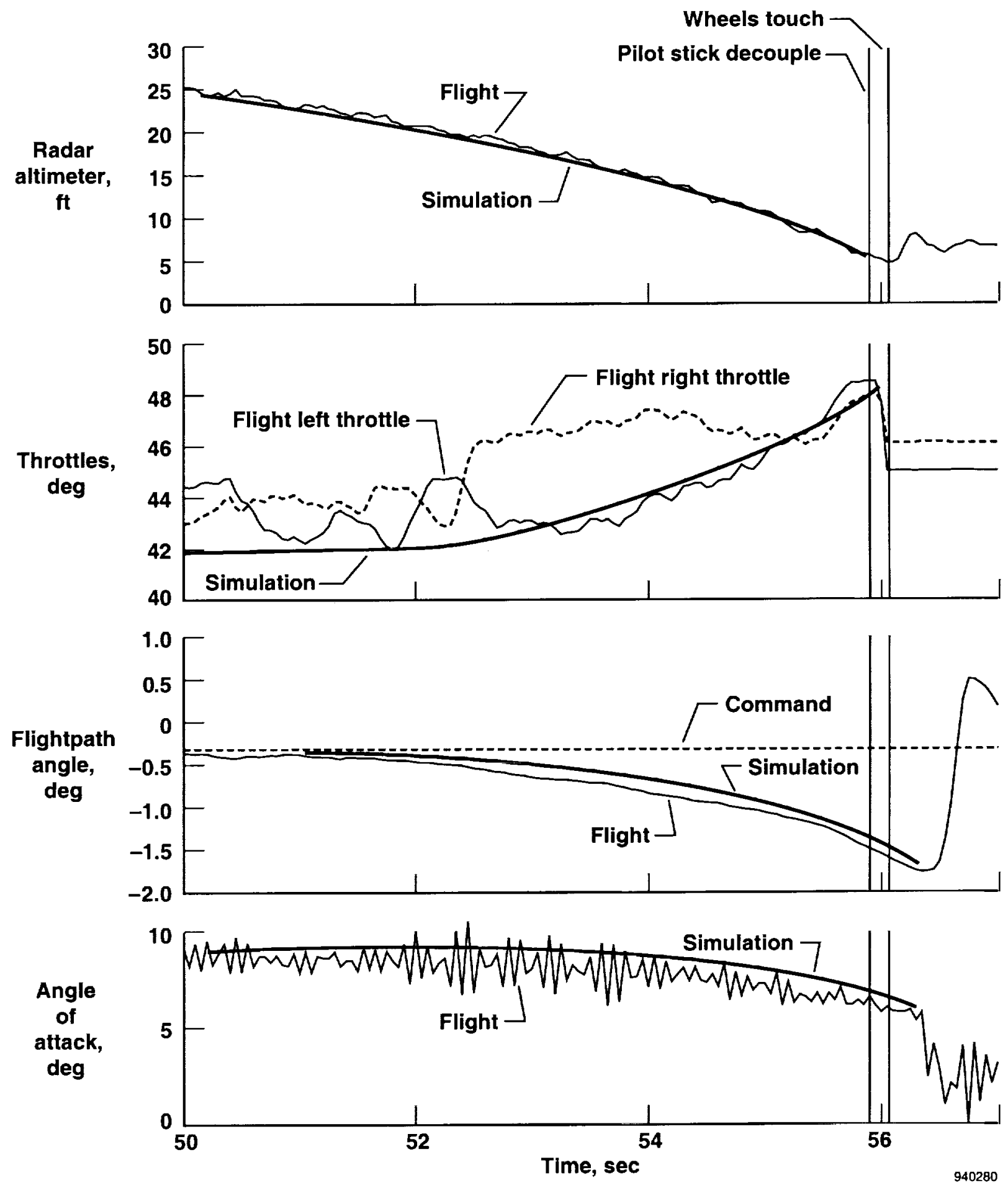

Figure 4. Ground effect influence on propulsion-controlled aircraft approach and landing. 


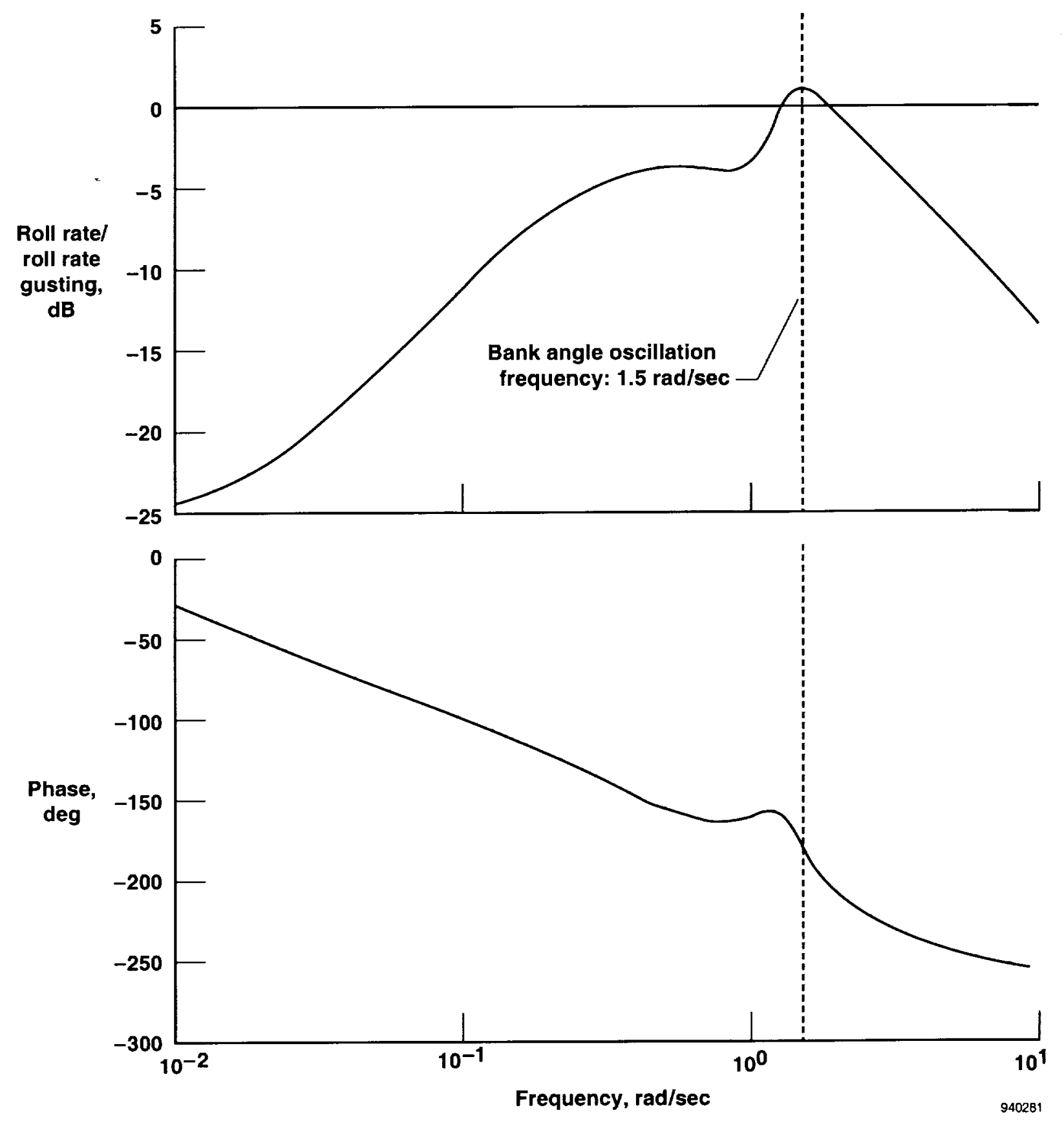

Figure 5. Linear open-loop roll rate response to roll rate gust disturbance.

When the conventional surfaces are disabled, roll rate sensitivity becomes an immediate concem. The engines, as the only available control effector, have a much lower control bandwidth than the stabilators. Engine bandwidth falls between 3 and $5 \mathrm{rad} / \mathrm{sec}$, depending on the specific operating point and flight condition. Furthermore, control power available from the engines is significantly smaller than that available from the stabilators. The maximum roll rate achieved from thrust differential is approximately $15 \mathrm{deg} / \mathrm{sec}$, which is an order of magnitude decrease in control power, a significant reduction in control effector bandwidth.
A linear analysis of the PCA lateral-directional control system driven by the Dryden gust model produced the Bode plot shown in figure 5. The figure shows the roll rate sensitivity of the F-15 airplane with the surfaces disabled to roll rate gust disturbances. A peak in the response occurs at approximately $1.5 \mathrm{rad} / \mathrm{sec}$ with a magnitude above the $0 \mathrm{~dB}$ line. This peak indicates that the F-15 airframe actually amplifies the effects of gust disturbances at this frequency. This characteristic manifests itself as a tendency toward bank-angle oscillation at a frequency of approximately $1.5 \mathrm{rad} / \mathrm{sec}$. This frequency is very close to the cutoff frequency of the engines where engine response 

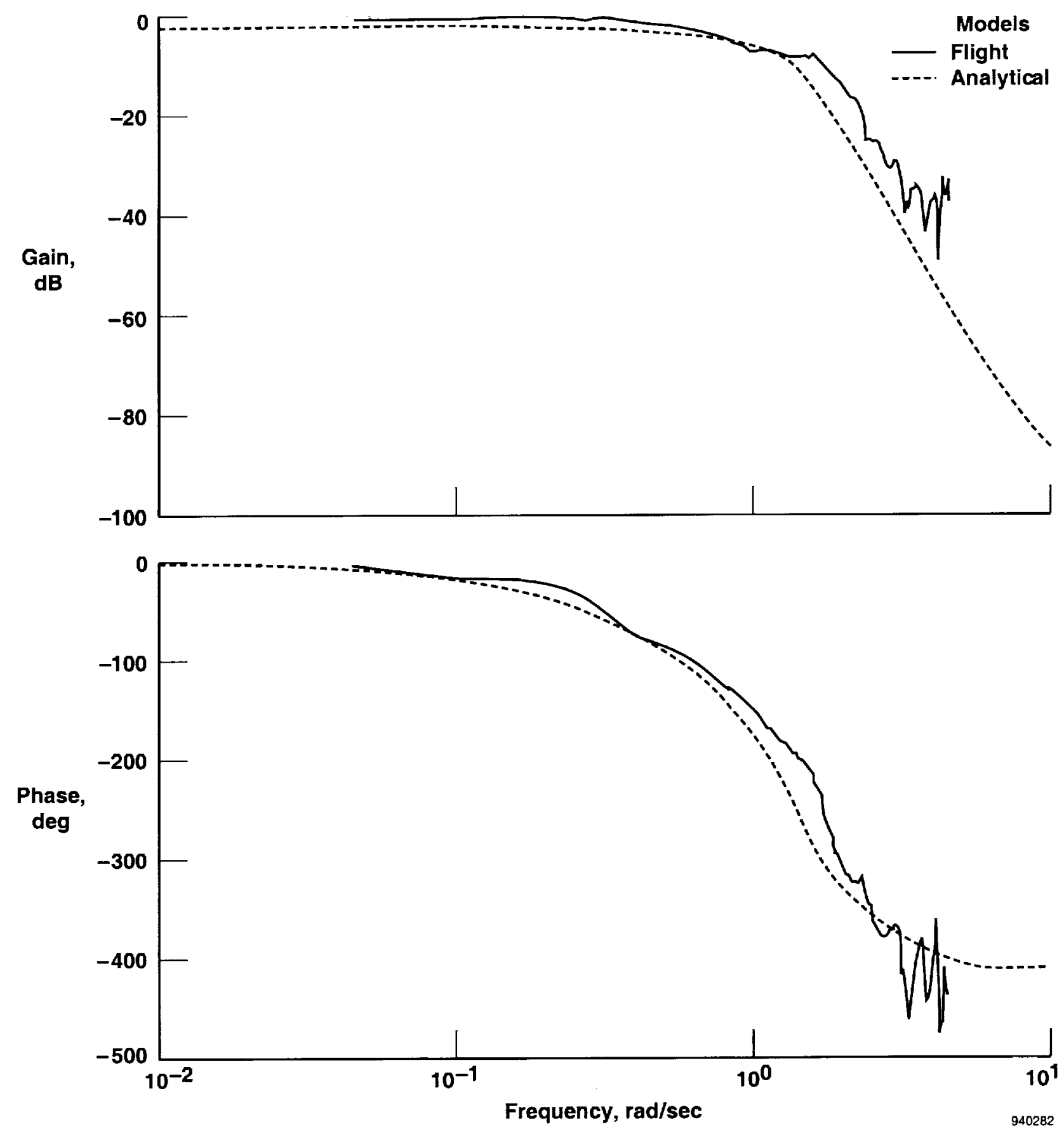

Figure 6. Propulsion-controlled aircraft closed-loop bank angle frequency response from flight and analytical.

lag becomes quite significant. This response lag poses a challenge to properly managing what little control power exists in this frequency range.

The combined phase lag from the engine dynamics and control system delays results in a large phase lag from the bank-angle thumbwheel to bank-angle response at the $1.5 \mathrm{rad} / \mathrm{sec}$ frequency. Figure 6 shows the analytical and flight-derived frequency responses of the closed-loop lateral response of bank angle to pilot command. The flight-derived response was determined through a pilot-conducted frequency sweep. At the bank-angle oscillation frequency of $1.5 \mathrm{rad} / \mathrm{sec}$, a phase lag of approximately $200^{\circ}$ exists. The phase lag in the feedback loops results in the control system amplifying rather than attenuating gust-induced roll disturbances at the bank-angle oscillation frequency. The NASA F-15 airplane was flown 
through turbulent air with the PCA system on and then was flown again through the same air mass with the control augmentation off. Comparisons of the power spectrum of roll rate activity show the control system amplifying roll rate disturbances by approximately 30 percent (fig. 7).

The disturbance amplification and command-to-bankangle phase lag at $1.5 \mathrm{rad} / \mathrm{sec}$ result in a condition in which a pilot-induced oscillation can easily occur. Figure 8 shows the pilot attempting to damp the gustexcited bank oscillation by applying a counter command. Instead of damping the bank-angle oscillation, the pilot is actually providing further excitation. This oscillation substantially complicated the landing task and limited the flight regime for this initial PCA demonstration program to relatively light levels of turbulence.

This program was a first demonstration of the feasibility of throttles-only flight control and did not seriously address the anticipated gust rejection problem. Relatively little effort was directed at designing control laws that would handle even light turbulence well. As the program progressed, the impossibility of ordering the weather to match the flight test schedule and the high level of success achieved in still air led to attempts to fly in increasingly turbulent air. In retrospect, a greater effort could have been made to design the control laws to reject gust disturbances. The relatively low engine response time and limited control effectiveness intrinsically limit the ability of the system to compensate for atmospheric disturbances. Aggressive use of lead in the control laws should be able to alleviate this limitation. The system had only first-order lead compensation in the lateral axis (fig. 2(b)). Faster engine response characteristics would also help.

\section{Cross-Coupling}

Cross-coupling between the longitudinal and lateraldirectional axes was observed. The cross-coupling can be classified into three types: dynamic cross-coupling, crosscoupling caused by engine thrust command limit saturation, and cross-coupling caused by performance differences between the engines.

Dynamic cross-coupling effects are evident at large bank angles. As bank angle increases, the vertical component of lift is reduced and an increase in airspeed is required to maintain flightpath angle. Using the PCA system, bank-angle response is significantly faster than flightpath angle response. The required changes in airspeed lag behind the bank-angle response to bank-angle command, thus creating a disturbance of flightpath angle.

Figure 9 shows the results of a bank-angle response test with a series of bank-angle commands of increasing magnitude. The normal thumbwheel scaling for the PCA control laws only permitted up to $30^{\circ}$ of bank command. This scaling was doubled for this test, allowing bank-angle commands of up to $60^{\circ}$. For the $15^{\circ}$ bank-angle commands, bank-angle tracking was good and resulted in minimal changes in airspeed or flightpath angle. At approximately $150 \mathrm{sec}$, the bank-angle command was increased to $35^{\circ}$. This increase resulted in approximately $5^{\circ}$ of overshoot to the bank-angle command, and the flightpath angle was disturbed to approximately $-5^{\circ}$. Additionally, the airspeed increased from approximately 150 to 180 knots to compensate. This is a speed where the adverse inlet airflow effect is present.

As the test continued, bank commands up to $25^{\circ}$ were accurately held, and the $35^{\circ}$ command again resulted in an overshoot to approximately $50^{\circ}$ and a loss of flightpath angle of $4^{\circ}$. When the command was returned to $0^{\circ}$ at approximately $500 \mathrm{sec}$, the energy acquired in the form of increased airspeed caused flightpath angle to increase and significantly overshoot the commanded flightpath angle. At high bank angles, stability began to suffer. At the extremes, bank angle commands of $60^{\circ}$ produced as much as $-10^{\circ}$ of flightpath angle disturbance and $20^{\circ}$ of flightpath upset on the rollout. Dynamic cross-coupling is a limiting factor on how much bank-angle command is usable. Commands below $25^{\circ}$ did not produce significant flightpath angle disturbances, but above $25^{\circ}$, the disturbances became increasingly severe. This limitation is reasonable for an emergency landing mode and could probably be addressed with a bank-angle crossfeed to the longitudinal control laws.

Cross-coupling caused by throttle command saturation typically occurred on landing approaches in gusty conditions. On low-speed approaches, the commanded collective thrust was close to idle. If the airplane was required to correct for a significant bank-angle disturbance, then the low collective thrust command combined with a differential command occasionally resulted in a throttle command which was below idle. This command saturation results in the degradation of both longitudinal and lateral control power. For the NASA F-15 airplane, keeping the wings level in turbulent conditions was difficult when using the PCA mode.

Figure 10 shows an effective loss of control power occurring between 41 and $43 \mathrm{sec}$. Both throttles were saturated at idle when a lateral disturbance occurred. The system commanded an increasing differential thrust command, but because both throttles were already saturated at idle, the portion of differential thrust command that would normally be achieved by lowering the right throttle was lost. The result was that only one-half the commanded differential thrust was achieved, and the system was unable to prevent a bank-angle excursion to $5^{\circ}$. Additionally, the resultant collective thrust was increased, causing a small increase in flightpath angle. 


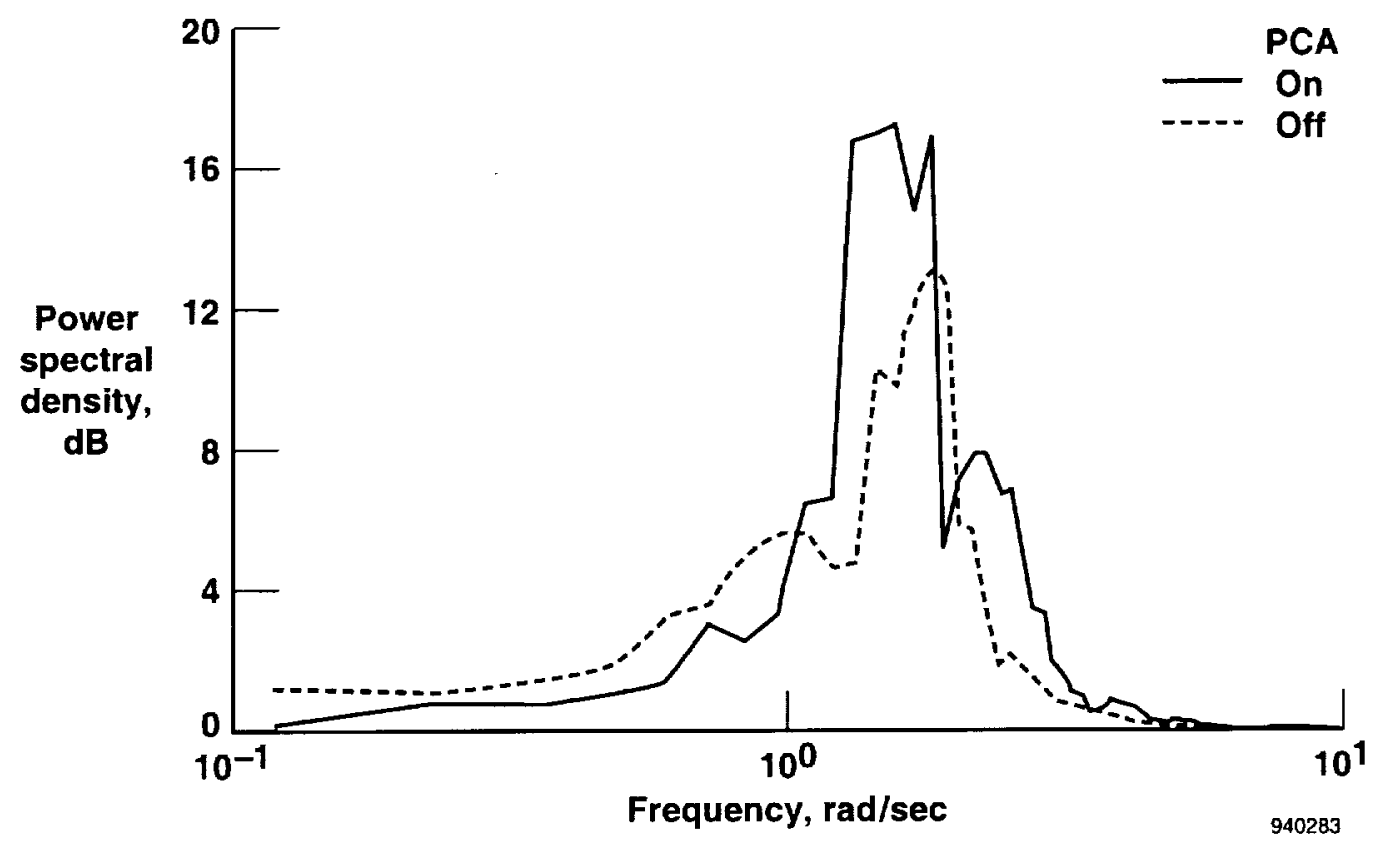

Figure 7. Roll rate power spectral density with and without the propulsion-controlled aircraft system during flight test. 

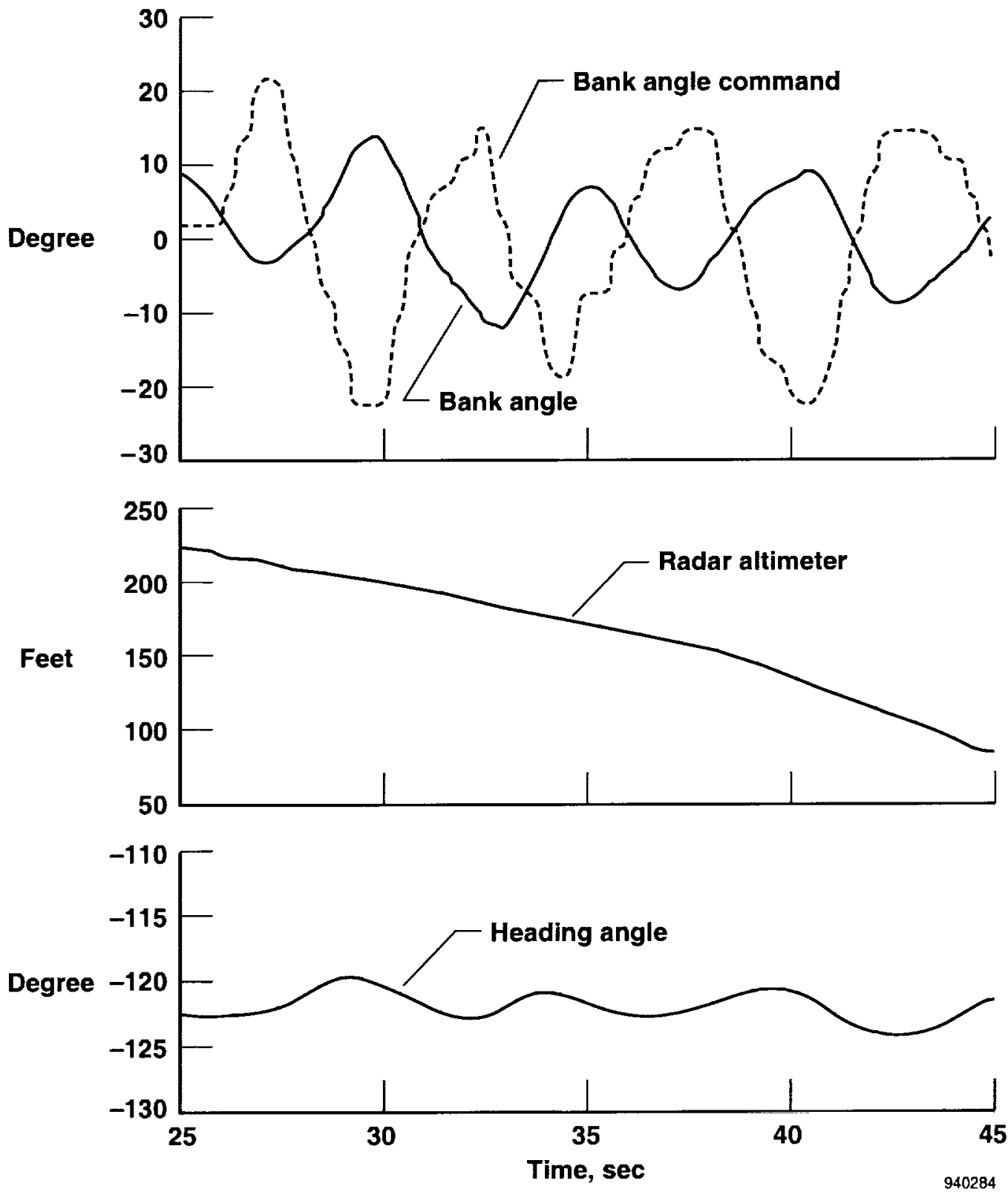

Figure 8. Lateral pilot-induced oscillation on propulsion-controlled aircraft approach. 

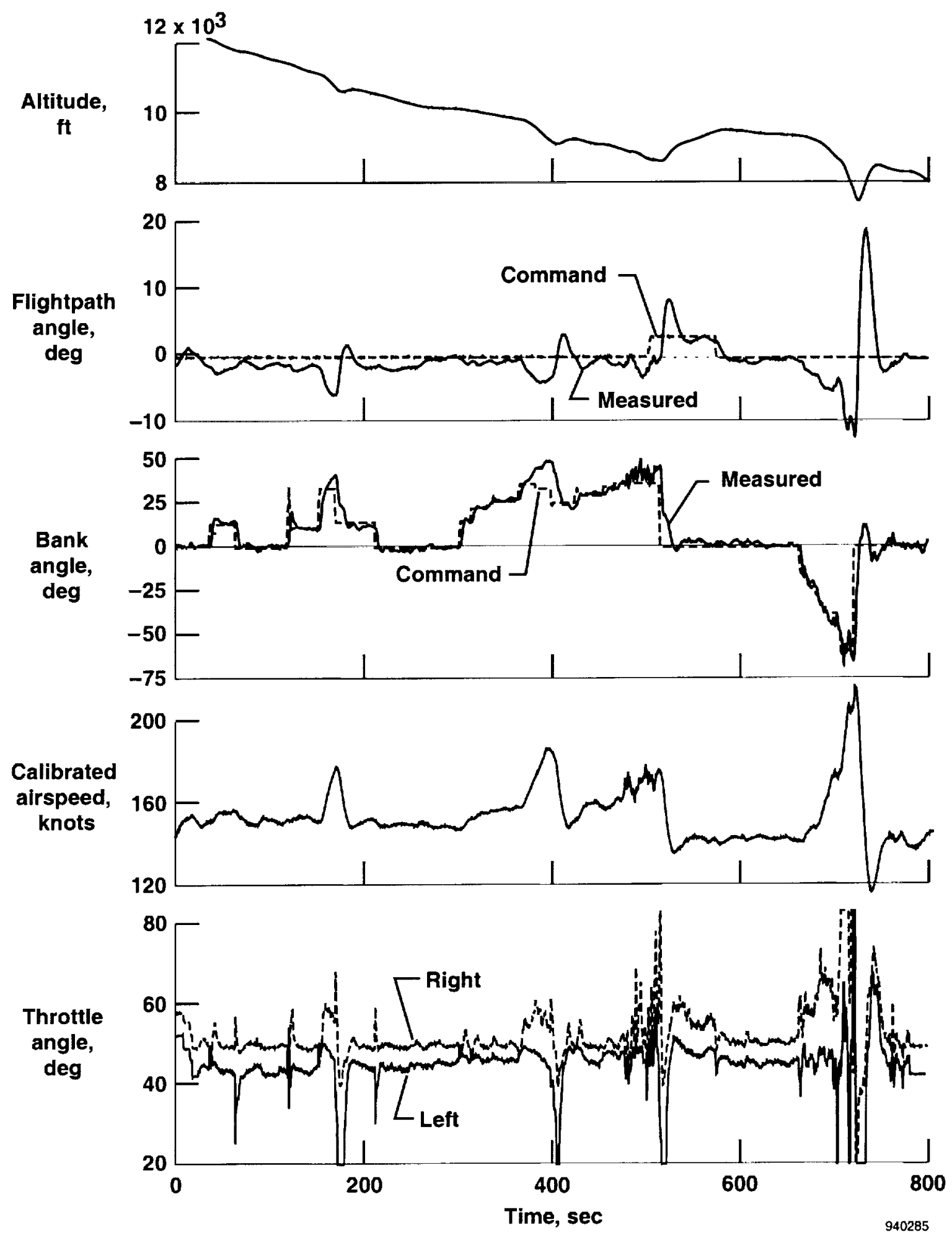

Figure 9. The F-15 propulsion-controlled aircraft maximum bank angle test with gear and flaps down. 

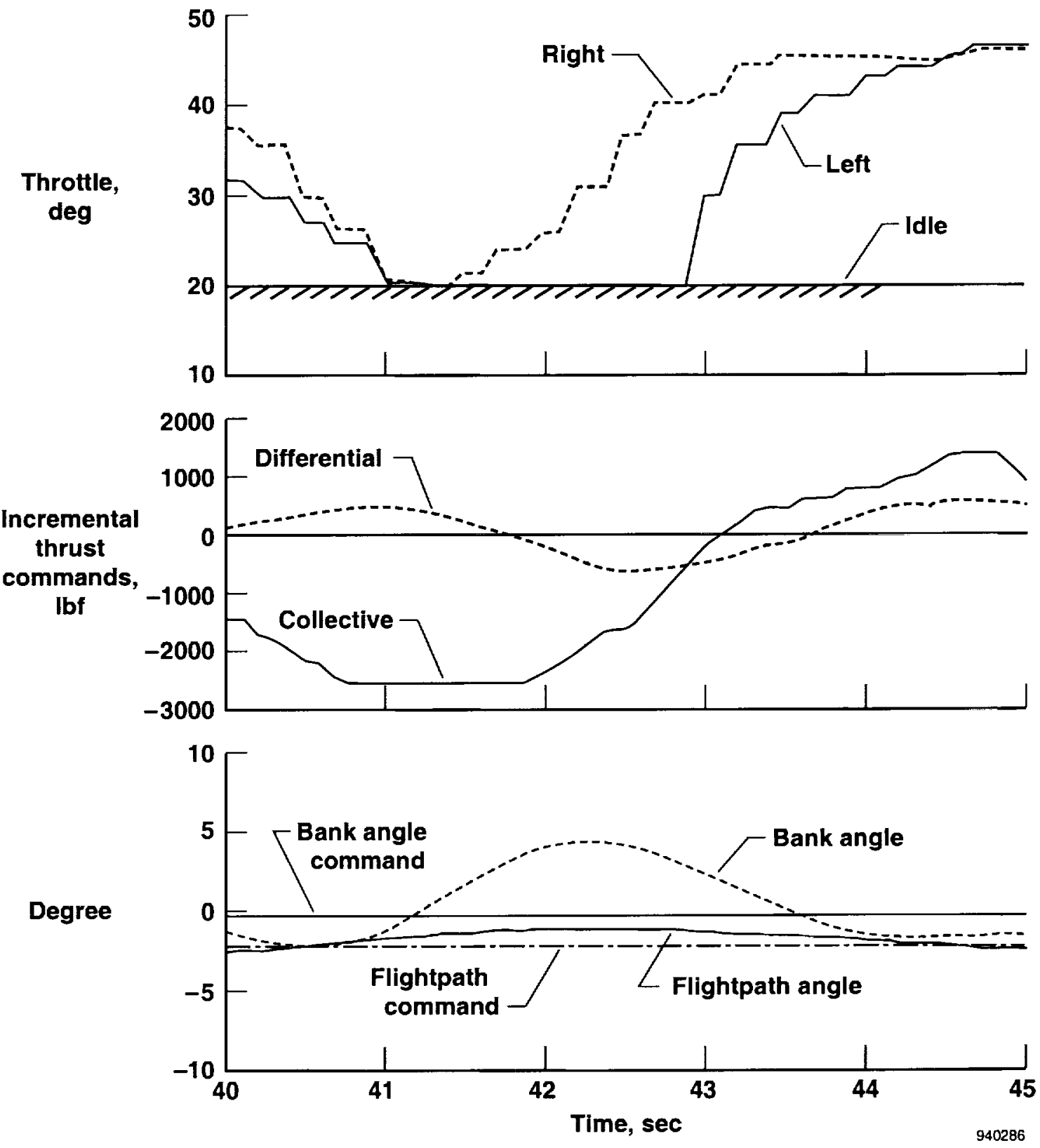

Figure 10. Cross-coupling response caused by propulsion-controlled aircraft command saturation. 
Performance differences between the engines also resulted in some cross-coupling. Because engine thrust is a nonlinear function of throttle angle, small differences in the initial throttle settings can introduce differential thrust as the collective thrust command changes. Conversely, changes in differential thrust can adversely affect the collective thrust. If the pilots did not consciously try to match the two engine fan speeds before trimming the airplane and engaging the PCA system, then a minimum of a $5^{\circ}$ difference in the throttle positions was typically carried throughout the test. Engines are never going to be as symmetrical as standard airplane control surfaces, but for production implementation, engine-control logic could be designed to match the engines prior to using PCA logic and thus minimize cross-coupling caused by performance differences.

\section{Concluding Remarks}

The NASA F-15 PCA program provided valuable experience with the problems likely to be encountered when using the propulsion system to provide flight control. The program succeeded in proving the feasibility of the PCA concept and helped clarify the nature and magnitude of the difficulties involved. Even though the success of the program relied heavily on simulation work, the program also uncovered many simulation deficiencies. Although these deficiencies would be negligible in other contexts, the deficiencies forced substantial changes to existing, well validated simulations and highlighted the need to take this type of project to actual flight test.

The adverse aerodynamic interaction of the inlet airflow and the airframe was the only unanticipated problem. The primary impact of this problem on the program was to force the use of a lower speed to maintain desired levels of control over the airplane, particularly for the landing task. Velocity feedback was also added to the control laws to partially compensate for the adverse interaction at higher speeds. Problems with adverse interaction are most likely to occur on aircraft with highly integrated propulsion systems, such as fighter aircraft, where inlet-airframe interactions are significant. The podded engines with simple inlets found on most subsonic airplanes should have minimal problems with inlet-airframe interactions.

Concern about potential problems caused by ground effect led to an early flight program to determine an accurate dynamic model of the response of this airplane to ground effect. This model was incorporated into the simulation and used to practice landings and develop piloting techniques. Unfortunately, the simulation did not accurately predict the performance of the PCA system when in ground effect. The two relatively hard touch-and-go landings led to a decision to not take any further approaches all the way to the ground. The interactions of the PCA system with ground effect were not adequately understood until after the program was completed.

During the conceptual stages of the program, getting the airplane safely on the ground using only the normal propulsion system for control in still air seemed sufficiently ambitious for a demonstration program. As a result, relatively little effort was directed at designing control laws that would handle even light turbulence well. Lateral control degraded significantly in the presence of turbulence. In retrospect, a greater effort could have been made to design the control laws to reject gust disturbances and minimize the likelihood of pilot-induced oscillation. The relatively low engine response time and limited control effectiveness intrinsically limit the ability of the system to compensate for atmospheric disturbances.

Future PCA designs would benefit from studying cross-coupling issues. Because aircraft landings are done at low speeds, PCA control designs are likely to saturate on idle. Explicit logic should be included in future designs to fully exploit the limited control effectiveness when saturation does occur. Engines are never going to be as symmetrical as standard airplane control surfaces, but engine control logic could be designed to match the engines prior to using PCA logic and thus minimize cross-coupling caused by performance differences. If the PCA control system is viewed as an emergency backup, the dynamic cross-coupling would probably not be a serious performance problem because high bank angles are not required for emergency landings. The system should, however, limit pilot authority to bank angles that do not cause significant cross-coupling.

\section{References}

'Burcham, Frank W., Jr., Maine, Trindel A., Fullerton, C. Gordon, and Wells, Edward A., Preliminary Flight Results of a Fly-By-Throttle Emergency Flight Control System on an F-15 Airplane, NASA TM-4503, 1993.

${ }^{2}$ Burcham, Frank W., Jr. and Fullerton, C. Gordon, Controlling Crippled Aircraft-With Throttles, NASA TM-104238, 1991.

${ }^{3}$ Gilyard, Glenn B., Conley, Joseph L., Le, Jeanette, and Burcham, Frank W., Jr., A Simulation Evaluation of a FourEngine Jet Transport Using Engine Thrust Modulation for Flightpath Control, NASA TM-4324, 1991.

${ }^{4}$ Burcham, Frank W., Jr., Maine, Trindel, and Wolf, Thomas, Flight Testing and Simulation of an F-15 Airplane Using Throttles for Flight Control, NASA TM-104255, 1992.

${ }^{5}$ Fullerton, C. Gordon, "Propulsion Controlled Aircraft Research," in 1993 Report to the Aerospace Profession: Thirty-seventh Symposium Proceedings, Oct. 1993, pp. 78-88. 
${ }^{6}$ Burcham, F. W., Jr., Burken, John, and Maine, Trindel A., "Flight Testing a Propulsion-Controlled Aircraft Emergency Flight Control System on an F-15 Airplane," AIAA-94-2123, June 1994. (See also NASA TM-4590, 1994.)

${ }^{7}$ Wells, Edward A. and Urnes, James M., Sr., Design and Flight Test of the Propulsion Controlled Aircraft (PCA)
Flight Control System on the NASA F-15 Test Aircraft, NASA CR-186028, 1994.

${ }^{8}$ Corda, Stephen, Stephenson, Mark T., Burcham, Frank W., and Curry, Robert E., Dynamic Ground Effects Flight Test of an F-15 Aircraft, NASA TM-4604, 1994. 


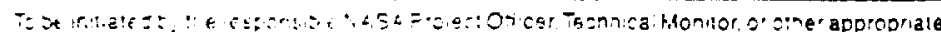

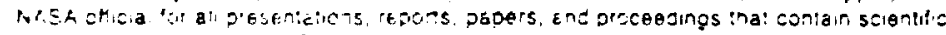

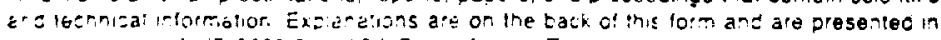

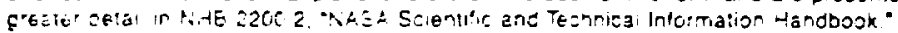

$X X X$ Orignal
$\vdots$ woditied

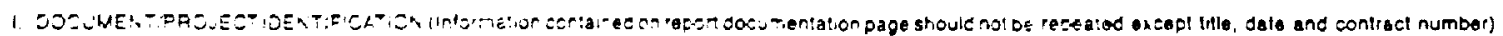

Tile Design Challenges Encountered in a Propulsion Controlled Aircraft Flight Test Program

aulporis, Trindel Majne (NASA), John Burken(NASA), F. W. Burcham(NASA), Peter Schaefer, UCLA, LA, CA (805) 258-3794

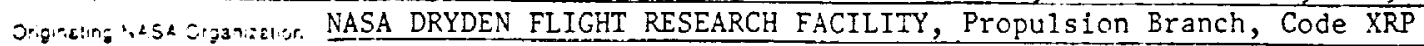

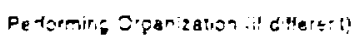

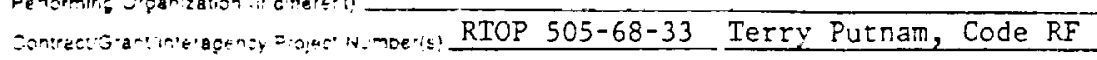

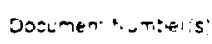

Documen: Date

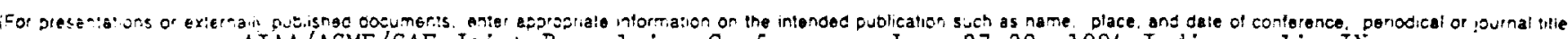

0 : Dow:tie ans puls,ie: AIAA/ASME/SAE Joint Propulsion Conference, June 27-29, 1994 Indianapolis IN

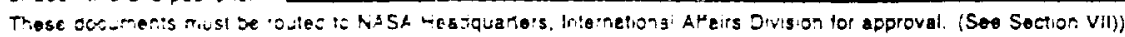

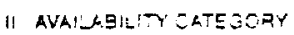

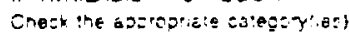

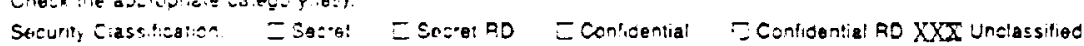

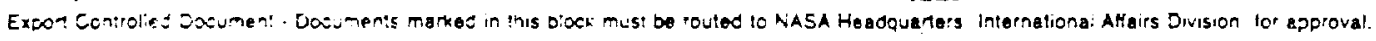

चTAR IEAR

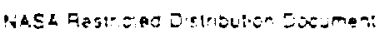

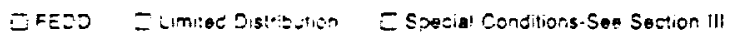

Documen' disciosing on invertion

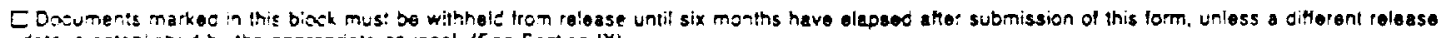

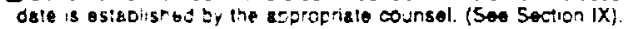

Publicly Averics' joiumen!

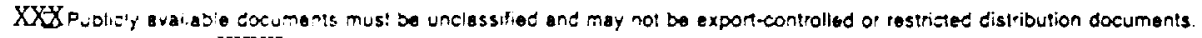

E Convighta: XXXKot copyrghied

II. SPECIAL CONDITIONS

Chock one o: more of the eqplisable bexes in each c! (a) eng (bj as the Sesis tor special restricted distribution it the "Special Conditions" box under NASA

Resiricied Distibuticr. Dacument in Section li is chocked. Guidelines are provided on reverse side of lorm.

a. This document contains

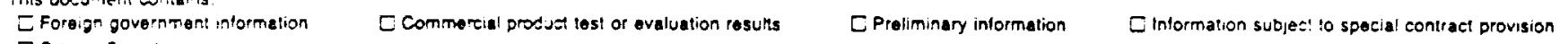

¿orner-Sposity

b. Check one of the lollowing limitations as appropriate:

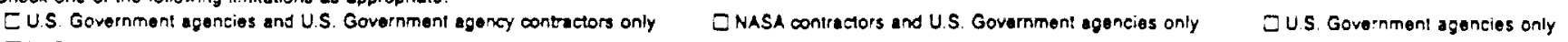

ENASA personsel and NASA contractors onty CNASA personnel only C Aveiiable only with approval of issuing office;

IV. BLANKET RELEASE (OFTIONAL)

All dxcumerits issued under the following contractgranuproject number

The olanke: relesse authorization granied _L_ is:

Z Rescinoed . Fulure documents must have individual evallability authorizalions. D Modifieg. Lifitations lor all documents procolsef in the STI system under may be processed as checkec in Sectons II and III.

V. PROJECT OFFICERIECHNICAL MONITOR

Dwain A. Deets, Acting Chief XR

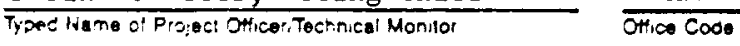
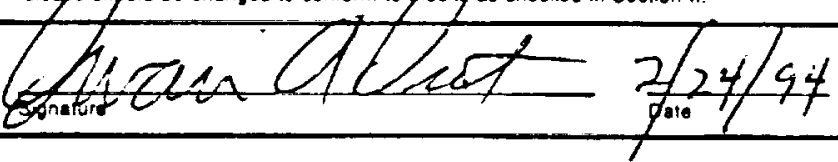

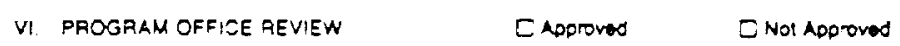

Typod Name of Progran OHice Fopresenialive

Propram Ottice and Coos

Signature

Oale

VI!. INTERNATIONAL AFFAIAS DIVISION AEVIEW

DOpen, domestic conteience presentation approved.

EForogr publicetigriproseniation approved.

C Export controlied limitetion is nol epplicable.

Expon controllod linitsion is approved.

En following Expon controllad limitation (ITAREAR) is assigned to this document:

Internaliong: Ahairs Der Fepresenlalive

Titie

Dato

VIII. EXPIRATION OF REVIEW TINE

The documanl is being rele esed in accorcance with the availability celogory and limitation checked in Section II since no objection was received from the Progf am

otfee wrthin 20 eeys of submission, as specified by NHB 2200.2. and approval by the Iniernational Affairs Division is not required.

Nane 1 Trtite

Orfice Code

Date

Note: This resese prococuio connot to used with documents designated es Export Controlied Documents, contelonce presentations or foreign publications.

IX. DOCUMENTS DISCLOSING AN INVENTION

- This document may releases on ___ Installation Patent or Intellectual P. sperty Counsol

b. The documenl was processect on $\frac{}{\text { Oele }}$ in accorconce with Sections II and III es applicable.

Oale

NASA CASI Dale

Date

\section{ABSTRACT ATTACHED}


National Aeronautics and Space Administration

Dryden Flight Research Facility

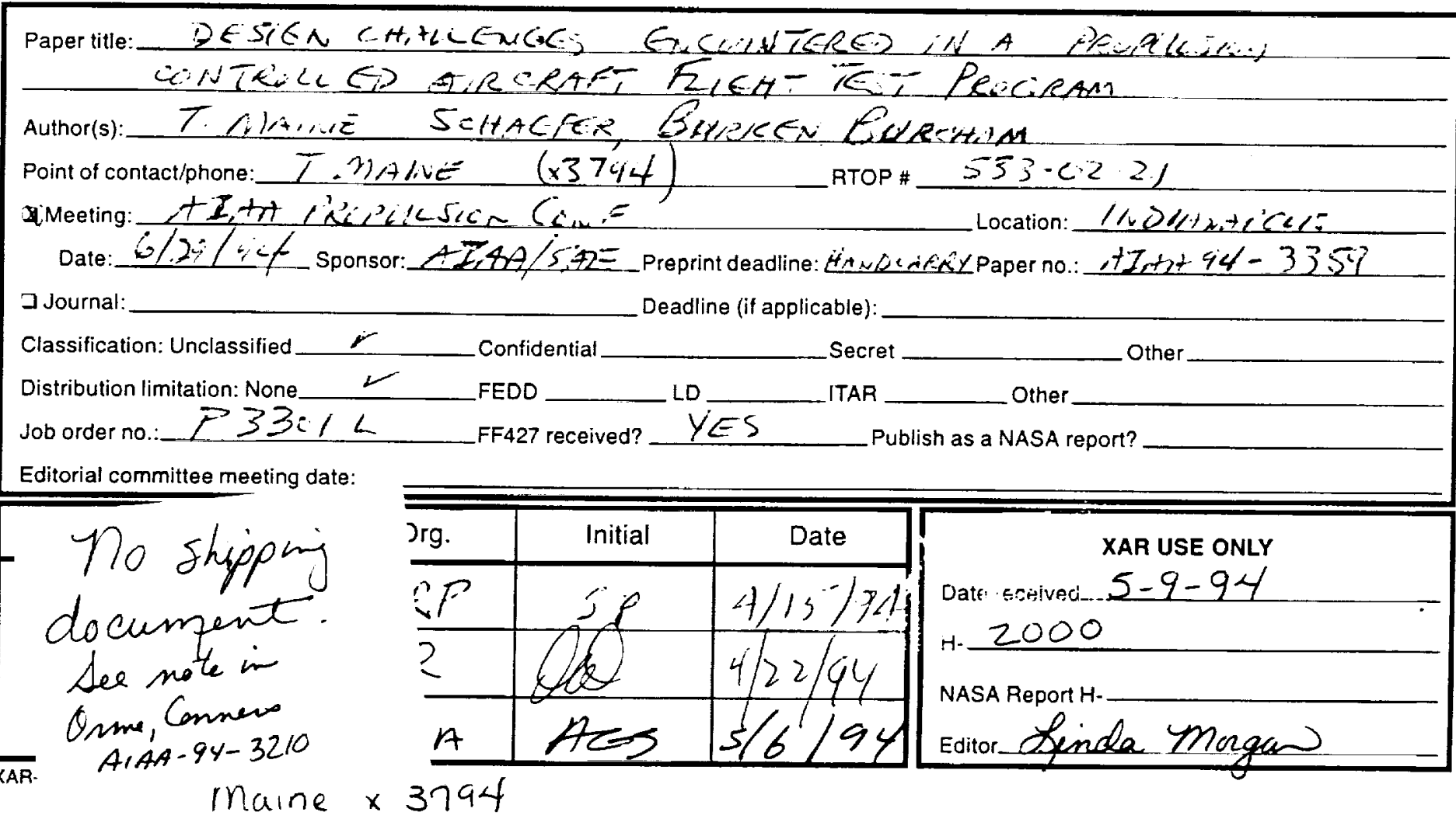




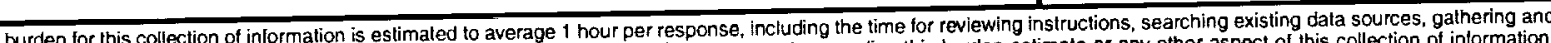
maintaining the data needed, and completing and reviewing the collection of information. Send comments regarding this burden estimate or any other aspect of this collection of intormation,

maintaining the data needed, and completing and reviewing Headquarters Sevices, Directorate for Information Operations and
including suggestions for reducing this burden, 10 Washington Hep
VA 22202-4302, and to the Office of Management and Budget, Paperwork Reduction Project (0704-0188), Washinglon, DC 20503.

\begin{tabular}{|l|l|l}
\hline 1. AGENCY USE ONLY (Leave blank) & $\begin{array}{l}\text { 2. REPORT DATE } \\
\text { June } 1994\end{array}$ & $\begin{array}{l}\text { 3. REPORT TYPE AND DATES COVERED } \\
\text { Conference Paper }\end{array}$ \\
\hline
\end{tabular}

\section{TITLE AND SUBTITLE
Design Challenges Encountered in a Propulsion-Controlled Aircraft}

Flight Test Program 5. FUNDING NUMBERS

6. AUTHOR(S)

Trindel Maine, John Burken, Frank Burcham, and Peter Schaefer

7. PERFORMING ORGANIZATION NAME(S) AND ADDRESS(ES)

8. PERFORMING ORGANIZATION

NASA Dryden Flight Research Center

P.O. Box 273

REPORT NUMBER

Edwards, California 93523-0273

H-2000

9. SPONSORING/MONITORING AGENCY NAME(S) AND ADDRESS(ES)

10. SPONSORING/MONITORING

AGENCY REPORT NUMBER

National Aeronautics and Space Administration

Washington, DC 20546-000 I

H-2000

\section{SUPPLEMENTARY NOTES}

Presented at 30th AIAA/ASME/SAE/ASEE Joint Propulsion Conference, June 27-29, 1994, Indianapolis, IN. AIAA Paper 94-3359.

12a. DISTRIBUTIONAVAILABILITY STATEMENT

2b. DISTRIBUTION CODE

Unclassified-Unlimited

Subject Category 05

13. ABSTRACT (Maximum 200 words)

The NASA Dryden Flight Research Center conducted flight tests of a propulsion-controlled aircraft system on an F-15 airplane. This system was designed to explore the feasibility of providing safe emergency landing capability using only the engines to provide flight control in the event of a catastrophic loss of conventional flight controls. Control laws were designed to control the flightpath and bank angle using only commands to the throttles. Although the program was highly successful, this paper highlights some of the challenges associated with using engine thrust as a control effector. These challenges include slow engine response time, poorly modeled nonlinear engine dynamics, unmodeled inlet-airframe interactions, and difficulties with ground effect and gust rejection. Flight and simulation data illustrate these difficulties.

\begin{tabular}{|c|c|}
\hline \multicolumn{2}{|l|}{ 14. SUBJECT TERMS } \\
\hline \multicolumn{2}{|c|}{$\begin{array}{l}\text { Aircraft control, Aircraft landing, Controllal } \\
\text { Flight tests, Research aircraft, Thrust control }\end{array}$} \\
\hline $\begin{array}{l}\text { 17. SECURITY CLASSIFICATION } \\
\text { OF REPORT } \\
\text { Unclassified }\end{array}$ & $\begin{array}{l}\text { 18. SECURITY CLASSIFICATION } \\
\text { OF THIS PAGE } \\
\text { Unclassified }\end{array}$ \\
\hline & \\
\hline
\end{tabular}

19. SECURITY CLASSIFICATION
OF ABSTRACT
Unclassified

20. LIMITATION OF ABSTRACT
Unlimited

